\title{
Cervical Spondylosis; An Inevitable But Preventable Catastrophe
}

Syeda Bushra Ahmed, Aisha Qamar, Muhammad Imran, Ambreen Usmani, Yasmeen Mehar, Sama ul Haque

\section{ABSTRACT:}

Cervical spondylosis is a chronic degenerative disease which is prevalent in middle and aging population. Its cause is multifactorial attributing to stress, anxiety, trauma, sports, occupational factors or use of handheld devices. It is easily missed and neglected as it has an insidious onset, early subtle features, and resemblance with musculoskeletal problems. It is essential to investigate and intervene because it places a significant impact on health care of individuals and can adversely affect lifestyle by causing depression, dysphagia, and cervicogenic headache along with chronic neck pain, which is ranked as the disabling cause of adjustable life years (DALY). It is responsible for causing minor symptoms like chronic neck pain, numbness in hands as well as even quadriparesis or spastic gait. It needs to be diagnosed and treated earlier. The state of art strategy adopted by health practitioners can be a promising future for the next generation. The objective of this article is to discuss the anatomy, etiology, prevalence, pathogenesis, clinical manifestations and treatment options.

Key Words: Cervical Spondylosis, Cervicogenic headache, chronic neck pain, disabling cause of adjustable life years.

\section{INTRODUCTION:}

The human body is supported at the back by a bony flexible structure called as the vertebral column, which is made of 33 vertebrae, out of which regional distribution is 7 cervical, 12 thoracic, 5 lumbar, 5 sacral and 4 coccygeal vertebrae. The vertebral column aids in weight bearing and flexible movements. The flexion is most considerable at cervical region while the extension is more evident at the lumbar region. It also protects the spinal cord and acts as a passage for important vessels and nerves through its foramina. The vertebral column also displays four curvatures; the anterior concavity at the thoracic and sacral region is called as thoracic and sacral kyphosis while posterior concavity at the cervical and lumbar region is called as cervical and lumbar lordosis. Cervical and lumbar lordosis are secondary curvatures attained during extension from the flexed state

Syeda Bushra Ahmed
M.Phil Student, Department of Anatomy
I Bahria University Medical and Dental College
Email: sbushra.ahmed@hotmail.com
Aisha Qamar
Professor, Department of Anatomy
I Bahria University Medical and Dental College
Muhammad Imran
I Consultant Radiologist and Head of Radiology Department, |
I Patel Hospital
I Ambreen Usmani
I Professor, Vice Principal and Head of Anatomy Dept.
I Bahria University Medical and Dental College
I Yasmeen Mehar
I Bssociate Professor, Anatomy
I Sahria University Medical and Dental College
I Assistant Professor, Anatomy
I Bahria University Medical and Dental College
I Received: 07-02-2019
I Accepted: 14-05-2019

during fetal development. Intervertebral discs in between vertebra cushions the vertebral column and act as a shock

Figure 1: Illustration showing curvatures of vertebral column

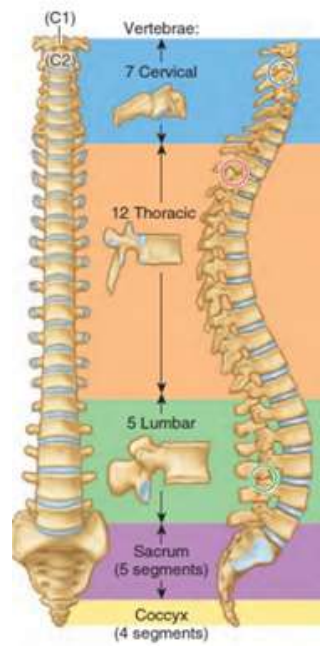

Figure 2: Cervical vertebra

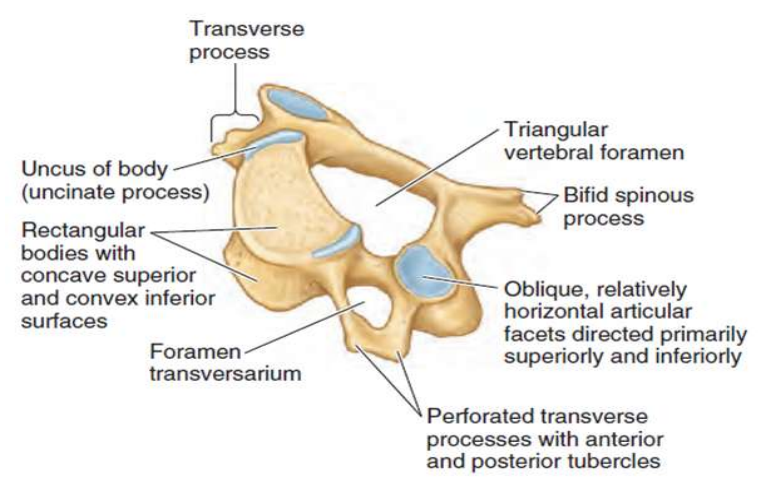

absorber. The intervertebral disc is made of an outer fibrous ring the annulus fibrosis and inner soft jelly-like material the nucleus puplosus ${ }^{1}$. 
Owing to the delicate structure and movements at cervical region, cervical vertebrae are prone to trauma, prolapse or degeneration which results in neck pain also called as cervicalgia. The cause of neck pain is multifactorial; it can be due to trauma, stress, anxiety, posture ${ }^{2,3}$, sports, occupational factors, usage of the computer or even mobile. A review done in Hong Kong showed that mobile phone usage is an essential cause of neck pain contributing around 17.3 to $67.8 \%$ as the prevalent musculoskeletal problem ${ }^{4}$.

A term Text neck and turtle neck ${ }^{5}$ have also been introduced by a U.S chiropractor Dr. Lean Fishman. It is due to the repetitive stress caused to the ligamentous or bony structures of the neck because of the forward head posture adopted during the use of electronic or handheld devices like computers, laptops and mobiles.

Neck pain is prevalent in the middle-aging population and primary cause of consultation worldwide ${ }^{6}$. It affects 30 to $50 \%$ of people. It causes a decreased range of motion and reduced muscle strength. $25 \%$ of patients attend physiotherapy clinics due to the complaint of neck pain ${ }^{7}$. Amid so many causes of neck pain and its aftermaths, cervical spondylosis is the most common cause in the middleaged population over 40 to 50 years, prevalent as 3.3 cases per 1000 people $^{8}$.

Cervical spondylosis severity is classified on the basis of osteophytes formation, intervertebral disc height loss, and vertebral plate sclerosis. This classification is in accordance with Kellgren and Lawrence osteoarthritis severity grade 9
It ranges from grade 0 to 4 as mentioned in table 1 below.

\section{METHODOLOGY:}

The methodology was undertaken by the following steps mentioned below;

1. Mapping exercise which includes identification of studies according to inclusion and exclusion criteria

2. Quality appraisal of studies

3. Data extraction

4. Analysis of findings

5. Conclusion

The steps were followed, and a comprehensive literature search was done using Google Scholar, Pubmed, Medline and Pakmedinet from the year 2009 onwards using keywords like cervical spondylosis, cervical spine, disc degeneration, and neck length. Grey literature in the form of books and clinical guidelines of international organizations was also searched for relevant references. The analysis of the data was done by thematic analysis technique, and narrative synthesis methodology was used to synthesize overall review findings.

\section{DEFINITION}

"Cervical spondylosis is a chronic degenerative process of the cervical spine that affects the vertebral bodies and intervertebral discs of the neck, and may progress into disc herniation, bone spur formation, compression of the spinal

Table 1: Scoring system based on Neutral Lateral Radiograph

\begin{tabular}{|l|ll|}
\hline 1. Height loss & & \\
Middle disc height compared to normal middle & $0 \%$ & 0 points \\
disc height at an adjacent level & $\leq 25 \%$ & 1 points \\
& $>25 \%-\leq 50 \%$ & 2 points \\
& $>50 \%-\leq 75 \%$ & 3 points \\
& $>75 \%$ & 4 points \\
\hline 2. Anterior osteophytes with respect to & No osteophytes & 0 points \\
the AP diameter of the corresponding VB & $\leq 1 / 8$ AP diameter & 1 point \\
& $>1 / 8-\leq 1 / 4$ AP diameter & 2 points \\
& $>1 / 4$ AP diameter & 3 points \\
\hline 3. Endplate sclerosis & No sclerosis & 0 points \\
& Detectable & 1 point \\
& Definite & 2 points \\
\hline Overall degree of disc degeneration $=1+2+3$ & 0 points (no degeneration) \\
& $1-3$ points (mild degeneration) \\
& $4-6$ points (moderate degeneration) \\
& $7-9$ points (severe degeneration) \\
\hline
\end{tabular}


Syeda Bushra Ahmed, Aisha Qamar, Muhammad Imran, Ambreen Usmani, Yasmeen Mehar, Sama ul Haque

cord, or cervical spondylotic myelopathy"10.

It is a broad spectrum of disease which causes syndromes as mentioned below. These are;

1. Cervical Radiculopathy: Compression of the cervical nerve roots due to osteophytes or vertebral plates clinically manifested as pain, paresthesia, motor deficits and diminished reflexes in the distribution of cervical nerve roots. The distinguishing feature between cervical radiculopathy and axial joint pain is the presence of pain on the unilateral side rather than bilateral as presented in axial joint pain ${ }^{11}$. It is the easiest syndrome to recognize ${ }^{12}$.

Clinical findings: It is characterized by neck pain with radiation to the upper extremity. The upper extremity signs and symptoms correlate with the specific nerve root compression, its characteristic reflexes, and sensory and motor weakness. Most common nerve roots to be affected are C6 (C5-C6 disc space) and C7 (C6-C7 disc space). In case of the $\mathrm{C} 6$ nerve root, there will be weakened biceps muscle, decreased brachioradialis reflex and sensory loss over the arm to thumb and index finger. The $\mathrm{C} 7$ nerve root impingement will cause weakened triceps, decreased triceps reflex and sensory loss to the middle finger ${ }^{13}$.

Signs characteristic for cervical radiculopathy are Spurling's sign; shoulder abduction test and manual traction to the neck $^{13}$. These provocative tests are also mentioned in table 2.

2. Cervical Myelopathy: This is degeneration of spinal structures as a result of the narrow spinal canal causing neurological signs and symptoms. The narrow spinal canal can be congenital, or due to the aging process of cervical spondylosis. In the Asian population, ossification of posterior longitudinal ligament appears to be the cause. It is the common cause of non-traumatic quadriparesis. Vitamin B12 deficiency is the sole nutritional reversal cause and should

Table 2. Provocative tests

\begin{tabular}{|l|l|}
\hline \multicolumn{1}{|c|}{ Test } & \multicolumn{1}{c|}{ Original Description } \\
\hline $\begin{array}{l}\text { Spurling's/Neck } \\
\text { Compression Test }\end{array}$ & $\begin{array}{l}\text { Passive lateral flexion, \& compression } \\
\text { of head. Positive test is reproduction of } \\
\text { radicular symptoms distant from neck. }\end{array}$ \\
\hline $\begin{array}{l}\text { Shoulder Abduction } \\
\text { (Relief) Sign }\end{array}$ & $\begin{array}{l}\text { Active abduction of symptomatic arm, } \\
\text { placing patient's hand on head. Positive } \\
\text { test is relief or reduction of ipsilateral } \\
\text { cervical radicular symptoms. }\end{array}$ \\
\hline $\begin{array}{l}\text { Neck Distraction } \\
\text { Test }\end{array}$ & $\begin{array}{l}\text { Examiner grasps patient's head under } \\
\text { occiput and chin and applies axial traction } \\
\text { force. Positive test is relief or reduction of } \\
\text { cervical radicular symptoms. }\end{array}$ \\
\hline L'hermitte's Sign & $\begin{array}{l}\text { Passive anterior cervical flexion. } \\
\text { Positive test is presence of “electric-like } \\
\text { sensations" down spine or extremities. }\end{array}$ \\
\hline Hoffman's Sign & $\begin{array}{l}\text { Passive snapping flexion of middle finger } \\
\text { distal phalanx. Positive test is flexion- } \\
\text { adduction of ipsilateral thumb and index } \\
\text { finger. }\end{array}$ \\
\hline
\end{tabular}

be screened in elderly ${ }^{14}$.

Clinical findings:

It has insidious onset starting from lower extremity as a disturbance in gait, balance and progressing to upper extremity with the clumsiness of hands, loss of grip, weakness in fine movements, neck stiffness, pain in upper limbs, bowel and bladder changes and multi-segmental weakness.

Signs characteristic for cervical myelopathy are Lhermitte's sign and Hoffman's sign ${ }^{15}$.

3. Axial joint pain: It is characterized by the pain in the joints and ligaments of the vertebral column. The pain is radiated to the shoulder, scapula, chest wall and head. There is no neurological involvement and pain in the joints is related to the activity. It is the most common clinical presentation, caused by improper posture and muscle fatigue due to ligamentous or muscular strain. Axial pain is nociceptive inflammation. Discography, steroid injection and radiography are important in its diagnosis ${ }^{17}$.

\section{FACTORS RESPONSIBLE FOR CERVICAL SPONDYLOSIS:}

Several factors are responsible for causing cervical spondylosis. Among them, patient characteristics like race, ethnicity, age ${ }^{6}$, height, and weight ${ }^{18}$ play a role as they are attributed to cervical dimensions. These characteristics and occupational factors like carrying heavy loads ${ }^{19}$ or using forward posture for an extended time like in computer workers or even mobile use is also presented as the cause ${ }^{20}$.

ADVERSE EFFECTS OF CERVICAL SPONDYLOSIS: Ischemic stroke:

Ischemic heart disease, ischemic stroke, diabetes, back pain, and neck pain are the main burden of illness in middle and low Socio-Demographic Index (SDI) countries due to obesity $^{21}$. Ischemic stroke accounts for about 20 to $30 \%$ which is mainly caused by atherosclerotic changes and emboli. The transient ischemic stroke mostly involves posterior circulation. The vertebral arteries and their branches constitute the vertebrobasilar system, which is responsible for supplying blood to the upper spinal cord, brainstem, cerebellum and small part of posterior cerebral hemispheres. The vertebral arteries ascend through transverse foramina of upper six cervical vertebrae and enter cranial cavity through the foramen magnum. They converge medially and unite at the back of the pontomedullary junction to form the basilar artery. The vertebral artery can be compressed by the uncinate process in the degenerative process of cervical spondylosis and increases the risk of posterior circulation ischemic stroke. This degeneration at vertebral plates, osteophytes formation, and disc height loss causes compression of the vertebral artery leading to vertebrobasilar insufficiency and eventually causing an ischemic stroke. Cervical levels prone to vertebrobasilar insufficiency are fifth and sixth (56\%), fourth and fifth (24\%), and sixth and 
seventh (20\%). Cervical spondylosis must be carefully and strategically assessed by clinicians and anticoagulant drugs be advised to such patients ${ }^{22}$.

\section{Depression:}

Depression is due to the poor health, lack of exercise, improper posture and is accelerated due to aging. People who suffer from depression are likely to have improper posture, disturbing the normal spine alignment and such individuals are more prone to develop spinal disorders like cervical spondylosis. A study revealed that there was a high risk of cervical spondylosis in severely depressed patients in comparison to the non-depressed group ${ }^{23}$.

\section{Cervicogenic Headache:}

It is the chronic hemi- cranial pain ${ }^{24}$ referred to the head from bony or soft tissues of the neck. It is caused by anatomical structures of the neck such as, the intervertebral disc between $\mathrm{C} 1-\mathrm{C} 3$ vertebrae, muscles, and ligaments supplied by upper three cervical nerves. The nociceptive afferents relay in the trigeminal nucleus and the pain is referred to trigeminal nerve territory, while the pain from the nociceptive afferents from the trigeminal system is also referred to cervico- occipital area. This pain must be differentiated from migraine and tension headache ${ }^{25}$.

\section{Dysphagia:}

Dysphagia $^{26}$ can also be observed in patients suffering from cervical spine disorders such as scoliosis, kyphosis, lordosis ${ }^{27}$ and in vertebral degeneration with the presence of osteophytes $^{28}$ and spinal cord injuries.

\section{CERVICAL SPONDYLOSIS IN ASYMPTOMATIC PATIENTS:}

$95 \%$ of asymptomatic individuals over age 60 to 65 years show at least one degenerative change in lateral cervical spine X-rays. It is a slowly growing process which is detected mostly with imaging. The diagnosis of cervical spondylosis should be not entirely on imaging, but history and physical examination should also be taken into account. Clinical correlation is highly recommended for such cases ${ }^{29}$.

\section{SHORT NECK LENGTH \& IT'S CORRELATION WITH CERVICAL SPONDYLOSIS:}

In a group of patients with cervical spondylosis, the neck length and cervical curvature were measured with the help of self-leveling plumb, level and square beam laser pointer, angle finder and level and laser level tape measure pro and were compared with healthy controls. It was found that patients with cervical spondylosis had decreased neck length and increased cervical curvature ${ }^{30}$.

The neck length and its association with cervical spondylosis need to be studied in our population as well, a majority of the Asian population is of short stature and as the disease is prevalent in middle-aged population so the condition should be intervened and screened in short height individuals.
There are currently no national or international standards for neck length ${ }^{31}$.

\section{PATHOGENESIS OF CERVICAL SPONDYLOSIS:}

Because of the degeneration at the intervertebral disc, these discs lose the water content, become soft and unable to bear the axial load at the cervical spine. Osteophytes form at dorsal and ventral margins and inside the vertebral canal to compensate for the load-bearing effect and cause compression of nearby neural and vascular elements. The disc loses its height, and as a result, the cervical spine loses its anterior concavity, that is, lordosis. Thus the cervical spine becomes kyphotic. The kyphosis can be removed surgically, either through ventral surgical fixation or combined ventral and dorsal approach of stabilizing fixation ${ }^{32}$.

\section{TREATMENT OF CERVICAL SPONDYLOSIS:}

Many treatment options are available for treating cervical spondylosis. They include conservative and operative management.

\section{Conservative management:}

Conservative management includes neck exercises, kinesiotaping, trans-cutaneous electrical nerve stimulation (TENS), medicines, acupuncture and percutaneous neuromuscular electrical stimulation.

\section{Neck exercises:}

According to a study, a 3-month isometric neck extension home exercise program along with NSAIDs restores physiological lordosis of the cervical spine and has proved to be beneficial in alleviating neck pain and its intensity. Asymptomatic individuals can even adopt the exercise program as cervical kyphosis can worsen with time and cause future complications. The exercise program can also be a better initiative to restore physiological curve rather than opting for surgery ${ }^{33}$.

\section{Mulligan's mobilization and Kinesiotaping:}

Mulligan's mobilization movement is a manual technique at gliding joints practiced by physiotherapist at the cervical region to ease the movements and make them pain-free. It involves natural apophyseal glides, reverse natural apophyseal glides, sustained natural apophyseal glides and mobilization with movements. Another method called as Kinesio taping, consist of a Kinesio tape which is a porous adhesive tape applied on the trapezius and paravertebral muscles under 5 $\%$ tension following the Kenzo Kase's KT muscle technique. Two strips in the form of I and Y are applied to ease pain and muscle movements. Copurgensli et al. used the concept of Mulligan's mobilization and Kinesio taping along with TENS and isometric exercises together for the treatment of neck pain caused by cervical spondylosis, and it proved to be beneficial as combination therapy rather than exercises alone ${ }^{34}$.

\section{Prayers:}


Syeda Bushra Ahmed, Aisha Qamar, Muhammad Imran, Ambreen Usmani, Yasmeen Mehar, Sama ul Haque

Islamic prayers, i.e. Namaz is obligatory for every Muslim. It involves the act of kneeling, bending, and prostration. They are beneficial for strengthening the neck muscles and protecting cervical vertebrae. The act of salam and sajdah proved to be beneficial in supporting and strengthening neck muscles. It has a significant role in the prevention of cervical spondylosis ${ }^{35}$.

\section{Percutaneous Neuromuscular Electrical Stimulation (PNMES):}

This involves use of PNMES device which gives electric current at a frequency of 2 to $100 \mathrm{~Hz}$ at acupoints of Jingjiagi on the back. It reduced the pain in the patients of cervical spondylosis. It has proved to be beneficial for acute and chronic cases as well ${ }^{36}$.

\section{HILT:}

Laser therapy has been widely practiced in musculoskeletal disorders like knee arthritis, shoulder pain, epicondylitis, and chronic ankle pain ${ }^{37}$. High Intensity Laser therapy and traction therapy were compared in short term, medium and long term follow up in patients with cervical spondylosis. HILT proved to improve range of motion and ameliorating pain. It could be the best therapeutic measure for long term management ${ }^{38}$.

\section{Pillows:}

Cervical pillows are recommended by physiotherapist as a part of the therapeutic strategy. It has been supported by a number of studies that the ergonomic latex pillow can effectively reduce neck pain in the long term follow up patients along with physical therapy ${ }^{39}$.

\section{Surgical management:}

Surgery is indicated for those who develop myelopathy or fail to respond to conservative treatment. Surgical management improves disease more promptly with less adverse effects. There are several surgical techniques including anterior, posterior, and combined approaches as well as Cervical disc arthroplasty, also known as total disc replacement. The Anterior approach yielded better results without exploiting the posterior neural elements. Variations of anterior approach also include Bailey-Badgley approach and Cloward approach ${ }^{40}$.

Most commonly anterior approach ${ }^{41}$ which includes anterior cervical discectomy and fusion (ACDF) has been practised due to its less invasive nature, as compared to the posterior approach which included laminectomy or laminoplasty with or without fusion ${ }^{42}$.

Cervical disc arthroplasty (CDA) has also emerged as a better option for cervical level 1 and 2 herniation and spondylosis. It preserved mobility at the segmental level and protected adjacent segment disease. The current study demonstrates it as the best strategy for preservation of a range of motion with less re-operation and adverse events ${ }^{43}$.

\section{CONCLUSION:}

Cervical spondylosis is one of the most common causes of DALY. It is prevalent in middle-aged as well as the aged population. The middle-aged population is an active group of society, and cervical spondylosis can deteriorate lifestyle and impact on the health of this major population. Considering the risk factors, adverse effects, pathogenesis, syndromes and treatment options, this disease needs to be further studied and correlated with the demographic, occupational and even neck length.

The neck length and its association with age, sex and the total height of the individual needs to be assessed and tested as a factor for cervical spondylosis in our population, because no study has so far been done in Pakistan correlating neck length with the incidence of cervical spondylosis. The neck length should be standardized in our population so that it can aid health caregivers and physiotherapist to obtain a standardized measure for evaluation and prevention of cervical spondylosis. Masses should be educated about the prevention of the disease by adopting healthy lifestyles, offering regular prayers, and maintaining good posture at the workplace. It is though a degenerative process which progresses with age, but its progression can be slowed down by focusing on prevention.

\section{REFERENCES:}

1. Moore KL, Dalley AF, Agur AM. Clinically oriented anatomy. Lippincott Williams \& Wilkins; 2009;215(4):474.

2. Kwon Y, Kim JW, Heo JH, Jeon HM, Choi EB, Eom GM. The effect of sitting posture on the loads at cervico-thoracic and lumbosacral joints. Technology and health care: official journal of the European Society for Engineering and Medicine. 2018;26(S1):409-18

3. Singla D, Veqar Z. Association between forward head, rounded shoulders, and increased thoracic kyphosis: a review of the literature. Journal of chiropractic medicine. 2017;16(3):2209

4. Xie Y, Szeto G, Dai J. Prevalence and risk factors associated with musculoskeletal complaints among users of mobile handheld devices: A systematic review. Applied ergonomics. 2017; 59:132-42.

5. Neupane S, Ali UTI, Mathew A, College MVS. Text Neck Syndrome - Systematic Review. Imp J Interdiscip Res. 2017; 3(7):141-8.

6. Binder AI. Cervical spondylosis and neck pain. Br Med J. 2007; 334(7592):527-31.

7. Sarig Bahat H, Feigelson E, Vulfsons S. The Potential Effect of Cervical Taping on Pain, Disability and Kinematics in Patients with Chronic Neck Pain-A Quasi-Experimental Study. Yoga Phys Ther Rehabil:2018;2018:1-9

8. Rudy SS, Poulos A, Owen L, Batters A, Kieliszek K, Willox $\mathrm{J}$, et al. The correlation of radiographic findings and patient symptomatology in cervical degenerative joint disease: A cross-sectional study. Chiropr Man Ther. 2015; 23(1):1-7.

9. Walraevens J, Liu B, Vander Sloten J, Goffin J. Qualitative and quantitative assessment of degeneration of cervical intervertebral discs and facet joints. European Spine Journal. 2009; 18(3):358-69. 
10. Wang C, Tian F, Zhou Y, He W, Cai Z. The incidence of cervical spondylosis decreases with aging in the elderly, and increases with aging in the young and adult population: A hospital-based clinical analysis. Clin Interv Aging. 2016; 11:47-53.

11. Pohl M, Back T, Leimert M, Seifert J, Stoffel M, Amelung RI, et al. Cervical Radiculopathy. Aktuelle Neurol 2018; 45(5):349-69.

12. Caridi JM, Pumberger M, Hughes AP. Cervical Radiculopathy: A Review. HSS J. 2011; 7(3):265-72.

13. Voorhies RM. Cervical spondylosis: recognition, differential diagnosis, and management. The Ochsner Journal. 2001;3(2):78-84

14. Amenta PS, Ghobrial GM, Krespan K, Nguyen P, Ali M, Harrop JS. Cervical spondylotic myelopathy in the young adult: A review of the literature and clinical diagnostic criteria in an uncommon demographic. Clin Neurol Neurosurg. 2014; 120:68-72.

15. Cook C, Brown C, Isaacs R, Roman M, Davis $\mathrm{S}$, Richardson W. Clustered clinical findings for diagnosis of cervical spine myelopathy. J Man ManipTher. 2010; 18(4):175-80.

16. Malanga GA, Landes P, Nadler SF. Provocative tests in cervical spine examination: historical basis and scientific analyses. Pain Physician. 2003;6(2):199-206

17. Eloqayli H. Clinical Decision-Making in Chronic Spine Pain: Dilemma of Image-Based Diagnosis of Degenerative Spine and Generation Mechanisms for Nociceptive, Radicular, and Referred Pain. BioMed research international. 2018; 2018:8793843.

18. Singh S, Kumar D, Kumar S. Risk factors in cervical spondylosis. J Clin Orthop Trauma. 2014; 5(4):221-6.

19. Oguntona SA. Cervical spondylosis in South West Nigerian farmers and female traders. Annals of African medicine. 2014; 13(2):61-4.

20. Ormos G. Survey of neck posture, mobility and muscle strength among schoolchildren. Man Medizin.2016; 54(3):156-62.

21. Kyu HH, Abate D, Abate KH, Abay SM, Abbafati C, Abbasi $\mathrm{N}$, et al. Global, regional, and national disability-adjusted life-years (DALYs) for 359 diseases and injuries and healthy life expectancy (HALE) for 195 countries and territories, 1990-2017: a systematic analysis for the Global Burden of Disease Study 2017. Lancet. 2018; 392(10159):1859-922.

22. Lin SY, Lin CL, Chen DC, Lee HC, Chen H Te, Lin TC, et al. Risk of posterior circulation stroke in patients with cervical spondylosis: A nationwide, population-based study. Atherosclerosis. 2018; 277(2):42-6.

23. Lin SY Sung FC, Lin CL, Chou LW, Hsu CY, Kao CH. Association of Depression and Cervical Spondylosis: A Nationwide Retrospective Propensity Score-Matched Cohort Study. Journal of clinical medicine. 2018; 7(11):387.

24. Vincent MB. Cervicogenic headache: the neck is a generator: con. Headache: The Journal of Head and Face Pain. 2010; 50(4):706-9.

25. Kawabori M, Hida K, Yano S, Iwasaki Y. Cervicogenic headache caused by lower cervical spondylosis. No shinkeigeka. Neurological surgery. 2009; 37(5):491-5.

26. Tian $\mathrm{W}, \mathrm{Yu}$ J. The role of $\mathrm{C} 2-\mathrm{C} 7$ and $\mathrm{O}-\mathrm{C} 2$ angle in the development of dysphagia after cervical spine surgery. Dysphagia. 2013; 28(2):131-8.

27. Papadopoulou S, Exarchakos G, Beris A, Ploumis A. Dysphagia associated with cervical spine and postural disorders. Dysphagia. 2013; 28(4):469-80.
28. Shih P, Simon PE, Pelzer HJ, Liu JC. Osteophyte formation after multilevel anterior cervical discectomy and fusion causing a delayed presentation of functional dysphagia. The Spine Journal. 2010; 10(7):e1-5.

29. Kelly JC, Groarke PJ, Butler JS, Poynton AR, O’Byrne JM. The Natural History and Clinical Syndromes of Degenerative Cervical Spondylosis. Adv Orthop. doi: 10.1155/2012/393642.

30. Taha M, Jafari FH, Kashyar P, Asad MR, Sami W, Fahad F, et al. Analysis of Neck Length and its Incidence for Cervical Spondylosis in Young Adults. J Rawalpindi Med Coll. 2014; 18(1):3-6.

31. Mahajan P V, Bharucha BA. Evaluation of short neck: new neck length percentiles and linear correlations with height and sitting height. Indian Pediatr.1994; 31(10):1193-203.

32. Ferrara LA. The Biomechanics of Cervical Spondylosis. Adv Orthop. 2012; 2012:1-5.

33. Alpayci M, Ilter S. Isometric Exercise for the Cervical Extensors Can Help Restore Physiological Lordosis and Reduce Neck Pain: A Randomized Controlled Trial. Am J Phys Med Rehabil. 2017; 96(9):621-6.

34. Copurgensli C, Gur G, Tunay VB. A comparison of the effects of Mulligan's mobilization and Kinesio taping on pain, range of motion, muscle strength, and neck disability in patients with Cervical Spondylosis: A randomized controlled study. J Back MusculoskeletRehabil. 2017; 30(1):51-62.

35. Pandey A, Singh AK, Kumar S, Chaturvedi M, Verma S, Agarwal P, et al. The prevalence of cervical spondylosis in Muslim community with special reference to Namaz in Agra. Internet Journal of Rheumatology and Clinical Immunology. $2017 ; 5(1): 1-5$

36. Miao Q, Qiang JH, Jin YL. Effectiveness of percutaneous neuromuscular electrical stimulation for neck pain relief in patients with cervical spondylosis. Med (United States). 2018; 97(26):1-4.

37. Kheshie AR, Alayat MS, Ali MM (2014) High-intensity versus low-level laser therapy in the treatment of patients with knee oste- oarthritis: a randomized controlled trial. Lasers Med Sci. 2014;29(4):1371- 1376

38. Ha $\mathrm{H}^{3}$ adaj R, Pingot M, Topol M. The Effectiveness of Cervical Spondylosis Therapy with Saunders Traction Device and High-Intensity Laser Therapy: A Randomized Controlled Trial. Med Sci Monit: international medical journal of experimental and clinical research .2017; 23:335-42.

39. Fazli F, Farahmand B, Azadinia F, Amiri A. A preliminary study: The effect of ergonomic latex pillow on pain and disability in patients with cervical spondylosis. Medical journal of the Islamic Republic of Iran. 2018; 32:81.

40. Kim LH, D'Souza M, Ho AL, Pendharkar AV, Sussman ES, Rezaii P, Desai A. Anterior Techniques in Managing Cervical Disc Disease. Cureus. 2018;10(8)

41. Peng B, DePalma MJ. Cervical disc degeneration and neck pain. Journal of pain research. 2018;11:2853-7

42. Audat ZA, Fawareh MD, Radydeh AM, Obeidat MM, Odat MA, Bashaireh KM, et al. Anterior versus posterior approach to treat cervical spondyloticmyelopathy, clinical and radiological results with long period of follow-up. SAGE. 2018; 6:1-7.

43. Chang C, Huang W, Wu J. The Option of Motion Preservation in Cervical Spondylosis?: Cervical Disc Arthroplasty Update. 2018; 15(4):296-305. 